\title{
Effect of Mobile Gaming on Mathematical Achievement among 4th Graders
}

\author{
https://doi.org/10.3991/ijet.v14i07.10315 \\ Mohammad Ahmad Al Khateeb \\ Hashemite University, Zarqa, Jordan \\ Mkm7879@hu . edu . jo
}

\begin{abstract}
This study aimed at identifying the effect of mobile gaming in mathematical achievement among the 4th graders. The study instrument was a math achievement test which consisted of (30) items of the multiple choice type (4 alternatives). The sample consisted of (66) students of the 4th grade in the City of Zarqa (Jordan), which was distributed over two groups: experimental groups $(n=34)$, and control group $(n=32)$. The researcher employed the experimental method on both groups. The experimental group was taught using the educational mobile games, and the control group was taught by the conventional method. The study found the use of mobile games an effective practice for providing educational support to the students in mathematics. In addition, the size of the effect of using mobile games was significant, a fact which supports the effectiveness of the mobile games in math achievement among the 4th graders.
\end{abstract}

Keywords-Achievement, gamification, math teaching, mobile gaming

\section{$1 \quad$ Introduction}

Many elementary school' students struggle to acquire the basic mathematical skills. Based on Trends in International Mathematics and Science Study TIMSS (2015), the mathematics mean of the 4th graders in Jordan was 388, much lower than, the international mean (508). Actually, several studies highlighted the poor performance of the students in mathematics; one striking example was that less than $10 \%$ of the students of classes (1-6) were able to solve the problem $(8+4=?+5)$ correctly (Carpenter et al., 2005).

Educational technology has long been regarded as a valuable approach to improve elementary school children's math achievement (Kebritchi, Hirumi \& Bai, 2010). According to the National Council of Teachers of Mathematics (NCTM, 2000), technology is essential in math teaching and learning, and that technology stabilizes math that had been taught and reinforces the students' learning. During the last three decades, different types of computer-aided programs were developed and taught. Results of the studies on this issue showed that technology has a positive effect on the students' achievement in mathematics (Cheing \& Slaving, 2013; Ferri et al., 2018; Li \& Ma 2010; Slavin \& Lake, 2008). 
Koutromanos \& Lucy (2014) indicated that the applications on the mobile appliances are able to become new methods of providing students with the educational content. While the mobile technologies play an increasingly significant role in the children's life everywhere, the ministries and schools are testing the use of these appliances to achieve learning and teaching objectives. The smart mobiles and tablets are among the new emerging technologies that may have a great effect in teachinglearning and research in the elementary education (Chun Ou, 2015; Sirkemaa \& Varpelaide, 2018; Zanchi, Presser \& Vahey, 2013), particularly in math subject.

Mobile appliances enjoy many valuable advantages as compared to the traditional gaming platforms. First, they are the more spreading throughout the world; currently, almost everybody has a mobile appliance. Furthermore, the mobile appliance is always with you, which enables you use it anywhere, and an advantage over the desktop computer. The latest mobile systems contain color screens of high resolution, clarity, high memory capacity, and rapid linking with the Internet, as well as many other advantages that make the mobile games more attractive (Robers \& Vanska, 2011).

The rapid development of the mobile systems creates new possibilities to learn math, as compared to the office and mobile computers. The mobile systems are light weighing and enjoy a longer battery life, as it could "survive" for an entire day without recharge. In addition, the touch screen is easier to use than the mouse or keyboard, and provides a better sensory experience by direct touch and physical movement (Koutromanos \& Lucy, 2014; Nicol, 2017; Zaranis, Kalogiannakis \& Papadakis, 2013). Segal (2011) found that the students who used a tablet with a touch screen better performed in the arithmetic and digital estimation as compared with those who used the mouse entries.

Gaming concept witnessed a remarkable change among the children due to the rapid changes taking place worldwide in the information technology age. While the children gaming is tied to their loud voices and collective laughs in an open space such as the house garden, the mobile gaming came as an inevitable result of the information leap, which has occupied our life with all its particulars. The young's interest shifted to the electronic, video and mobile gaming, which succeeded in attracting both the young males and females (Huizenga et al., 2009, Miller \& Robertson, 2011).

The mobile game makers succeeded in attracting large numbers of users who are highly fond of the computerized games, particularly the children and adolescents. In this concern, the innovated designs, the renewable ideas of these computerized games, the ease of using the mobile telephones, and possibility to take them wherever they go, all led to the addiction of the vast majority of children and adolescents on the use of the games in their mobile telephone. As such, the mobile gaming industry managed to attract the children due to many factors. Certain factors are connected to the technical aspects, and others are due to mobile spread over and the ease of use. Their success is also ascribed to being an entertainment way that provides children opportunities to discover and experiment, without the risk of responsibility or punishment (Admiraal, et al., 2011; Hursen. \& Bas, 2019; Seidg, 2008).

Many studies indicated the significance of educational mobile gaming use among learners. They integrate learning with pleasure and suspense; thereby increase their academic achievements, and develop their creative thinking through innovated meth- 
ods. They further contribute to the teaching individualization, allowing the learner to progress in his/her learning the way it fits his/her abilities and speeds learning, without shy or fear (Bicen \& Kocakoyun, 2018). The study of Kebritchi, Hirumi \& Bai (2017), and Seow Wong (2016) showed that the educational mobile gaming increases the student's achievements in various educational stages, and in different academic subjects, such as mathematics, English, and others.

The study of Christothea (2018) and of Koutomanos and Lucy (2014) emphasized the importance of the mobile gaming in providing scientific concepts. Miller and Robertson (2010) and Wang Huang and Hsu (2017) asserted the importance of the mobile gaming in the development of the student's scientific skills, such as computer use skills, social media skills, reading skills, and self-learning skills. Finally, study of Diah, Ehasn \& Ismail (2010), Franklin \& Peng (2008) and Wijers, Jonker \& Drijvers (2010) indicated the importance of the mobile gaming in increasing the motivation level with the students toward teaching and stimulating their mental abilities.

The above studies show that the mobile gaming provides the learners a chance to see things in ways totally different from what they are. Games can do this without going through details or extensive explanations, which lead to the learner's mental dispersion. Learning through mobile gaming is superior to learning from the books, as it is more successful in communicating the information, because it fills the gap between the student and the academic subject (Fabian, Topping \& Barron, 2016; Huizenga, Admiraalm Akkerman \& Dam, 2009).

The researcher observed the students' passion in using the games in their mobile telephones. They tirelessly spend their free time playing, and based on this fact, the researcher believes that employing a pool of mobile games that includes the mathematical concepts may lead to provide these concepts to students. Based on the previous studies, the researcher concluded that it is important to design an attractive and innovative mobile way that contributes in providing the student with mathematical concept. This may lead to an increase in the positive effects of the mobile games in the students' math achievements. Accordingly, the study attempts to answer the question: what is the effect of the mobile gaming in math achievement of the 4th graders? Therefore, the study seeks to design mobile gaming that could be used through the mobile telephones, and identify the effect of these games on the math achievements.

This study may benefit the curriculum and the academic subjects designers through focusing the attention to the preparation of mobile games, which contributes in developing the student's acquisition of different concepts. It further benefits the educational supervisors through holding training courses for the math teachers, to provide them with skills for designing mobile games according to specific criteria and controls. Teachers also may benefit from it through understanding the best ways to apply the mobile gaming in math teaching, and provide educational environment that encourages students to interact and participate. Parents also can make use of it through introducing them to the importance of the educational mobile gaming in facilitating their children's learning. Finally, it widely opens new educational mobile gaming-based research horizons and prospective, and provides particulars of their effects in many aspects, such as improving the academic achievement, developing the thinking styles, providing values, and other advantages. 


\section{Method}

The quasi-experimental design was used to investigate the effect of mobile games on mathematical achievement among 4th grade students. This design requires the following groups:

- The experimental group: Consisted of design, who studied "mathematics" using mobile games.

- Control group: Consists of design, who studied "mathematics" using the conventional method.

\subsection{Study sample}

The study was applied to a sample of 4th grade students, who studied "mathematics" in Zarqa City (Jordan) during the first semester of the year 2018/2019, due to the importance of the 4th grade. Where the Ministry of Education of Jordan considers this grade a stage through which it can enable students Understand the different math ideas. Furthermore, the TIMSS exams are designed based on this grade, because there is a similarity in the content of the Jordanian, European, and American mathematics textbooks for the $4^{\text {th }}$ grade in the fields of numbers, geometry, algebra, statistics and probabilities, as they are all built in the light of the NCTM. (Note: this is the adopted 4th grade math book for all Jordanian schools). The sample was randomly distributed over the study groups: group one $(\mathrm{n}=34)$ taught using mobile gaming, and group two $(\mathrm{n}=32)$ taught by the conventional method.

\subsection{Achievement test}

The researcher built a test consisting of (30) multiple-choice types, by analyzing the content of the mathematical textbook, and building the specification table, based on the National Assessment of Educational Progress (NAEP) levels of the educational objectives. Namely: conceptual knowledge, procedural knowledge and problem solving, the test was presented to the reviewers to verify its validity, and the test was modified in light of the reviewers' feedback. The researcher applied the test on an exploratory sample, and computed the difficulty coefficients ranging between 0.28 and 0.78 , the discrimination coefficients, which ranged between 0.29 and 0.81 . The reliability of the test was verified by Cronbach Alpha (0.83), which is an educationally acceptable value, The researcher used the test before the experiment to verify the parity between the experimental and control groups, and then after the experiment to detect the existence of differences statistically significant between the two groups.

\subsection{The educational mobile games}

The Dick and Carey model and the SMSE model associated with mobile learning content were combined and consisted of the following stages: Scenario, Message, Synchronization and Evaluation, In the light of the learning program nature in the 
study, which combines these stages in the Dick and Carey model for the production and development of educational materials, the model used in this study appears in Figure 1.

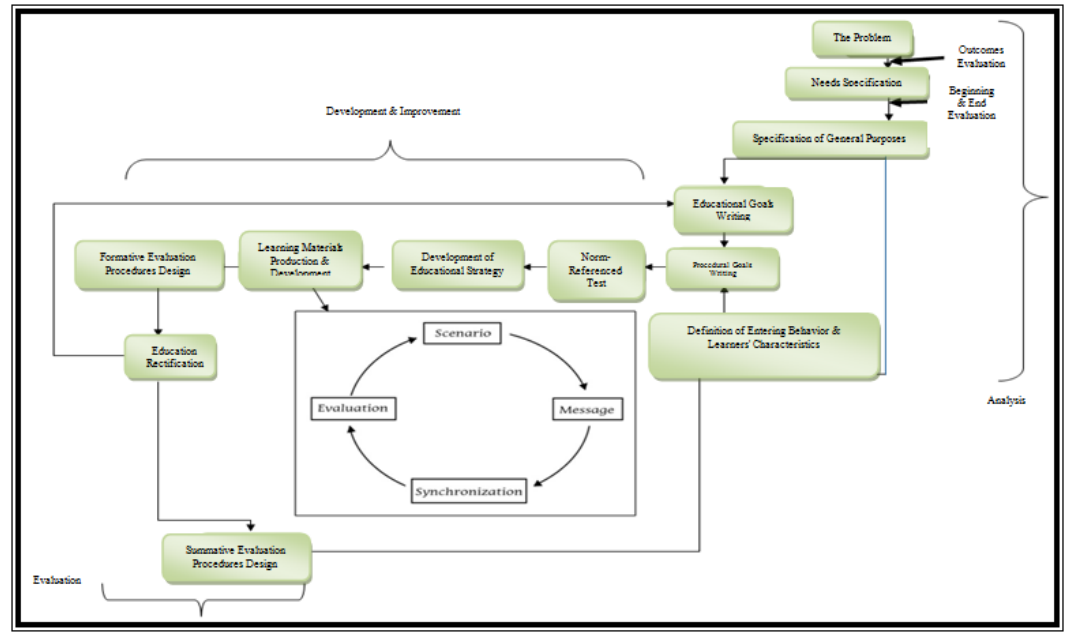

Fig. 1. The suggested learning model design

The researcher designed and produced mobile games, in order to use them in the teaching of the experimental group; to detect their impact on mathematical achievement, and so the researcher followed the following Stages:

Stage one: analysis and writing goals: The analysis stage is one of the basic stages in designing a suitable educational environment for teaching and for the use of mobile gaming. To achieve this, the researcher carried out the following:

- Specifying the general objectives of the educational content in the mobile games. The general purpose of designing the mobile games is providing the students with the mathematical concepts stated in units four and five (Fractions and Fractional Numbers/Decimal Fractions).

- Determining the educational content in the mobile games. The educational content in the mobile games included the math concepts, which resulted from the academic content of the unit (Fractions and Fractional Numbers/Decimal Fractions). In this concern, the analysis resulted in 10 mathematical concepts.

- Defining the Learners' characteristics and needs. In the current study, 4th graders are the beneficiaries of using the mobile gaming. Therefore, care should be taken regarding their needs, tendencies and abilities when we design and produce these games. We are also required to decide the learners' characteristics of the current study through the following:

- The students possess good experiences in the use of the mobile telephones and their different applications.

- Most of the students want to learn with the mobile telephones applications. 
- Students tend to compete at the individual level at first, then at the group level thereafter.

- Students, during the learning process, need what stirs their imagination and launches challenges to their minds. Students generally tend to be curious, seek exploration, experimenting and discovering new things.

- They continuously try to link the knowledge they study with examples of the factual surrounding environment.

- They prefer the instant enhancement after providing correct answer, particularly in the individual contests.

Stage two: development and improvement: This stage is related to the preparation of a detailed description of all the processes of the operations and components of the mobile games. Therefore, the researcher reviewed the literature and scientific references concerning designing the mobile games to explore the technical and educational criteria that should be adopted when we design such kind of games. Especially, the games used in the current study are practiced by the smart telephones, which add more criteria and conditions due to the differences of the smart mobile telephones capabilities from other appliances used in gaming, such as the small sized screen, possibility of playing through the touch technology, freedom of moving during the game and so on. During the design stage, in this Stage, the integration of the SMSE model was used in the tutorial design steps where the researcher implemented the SMSE model; the researcher conducted the following procedures:

- Phrasing the procedural objectives: The researcher phrased the objectives in a procedural manner, and presented them to a pool of arbitrators to show their views and comments. In the light of their comments, the researcher made the relevant amendments, which led to produce the list of the educational objectives in its final shape.

- Designing the suitable educational content of the mobile gaming: The researcher organized the educational content of the subject to be taught using the mobile gaming in the light of the predefined educational objectives. The content elements were coined by two ways:

- Phrasing the educational material in the form of abbreviated information, so that they are presented to the user before starting the games, to help him/her in achieving the assignments, overcome the obstacles, and realize winning.

- Phrasing the educational material in the form of various questions, so that they are presented to the game user during practicing the game. Therefore the student should answer correctly to allow him/her proceeds in the game and win.

- Designing the mobile games: After defining all the educational and technical specifications of the games, the researcher developed a vision of the mobile games that may be appropriate to the subject matter of the current study. He took into account that they should fit the age group of the 4th graders. To design these games, the researcher carried out setting designs of all the interfaces, graphical objects, and play environments of each game, Selecting the still and moving images and sound effects appropriate to each game, Selecting the type of clear scripts with attention so that the size and color of the script should be suitable for the play environment, De- 
signing interactional buttons the player uses to start or exit the game and other functions, Giving the game an interesting and relevant name and designing the number of the levels it includes. Accordingly, a game that included 9 levels was developed.

- Distributing the educational content over the mobile game: The researcher distributed the educational content over the different game levels. The math concepts to be provided to the students were determined at every level, to achieve the current study objectives. Table (1) illustrates the math concepts distribution over the game levels.

Table 1. Distribution of the mathematical concepts on the levels of the games

\begin{tabular}{|c|c|l|}
\hline Game Title & Level & \multicolumn{1}{|c|}{ Math Concepts } \\
\hline Math Helicopter & 1 & Equal Fractions \\
\cline { 2 - 3 } & 2 & Fractions Simplification \\
\cline { 2 - 3 } & 3 & Conversion of the fractional number to a fraction and vice versa \\
\cline { 2 - 3 } & 4 & Adding the fractions and the fractional Numbers \\
\cline { 2 - 3 } & 5 & Subtracting the fractions and the fractional Numbers \\
\cline { 2 - 3 } & 6 & The decimal fractions \\
\cline { 2 - 3 } & 7 & Parts of 10 \\
\hline & 8 & Parts of 100 \\
\cline { 2 - 3 } & 9 & Decimal numbers \\
\hline
\end{tabular}

Designing the interactional interfaces in the mobile games. User interface is all that the learner sees of elements, and all that interacts with him/her of tools on the screen. It includes all the system components, its different functions, as well as all the icons, buttons and links, which help the learner in the navigation process, and provide access to the different elements of the system. Accordingly, the researcher divided the designs of the interactional interfaces of the educational mobile games into six parts, as follows:

- Main game interface: It was designed in an attractive manner with music in the background. It contains the name of the game, an enter button and a button to move to the screen around the game (Fig. 2).

- Game level interface: It includes a number of the game levels. The player must achieve winning in a certain level to enable him/her move to a higher level. After achieving the winning in all the game levels, the player can choose the level he/she wishes, and the time he/she wishes.

- Information interface: It includes a part of the educational material in the shape of brief information, the interface appears to the user before he/she starts playing, to help him/her achieve the educational assignments, face the graphical objects, and realize winning.

- Game environment interface: It is the playground that includes the educational tasks in the form of question that needs an answer. In addition, it includes the graphical objects that require the player make correct answer toward them, to enable him/her accomplish the educational tasks and achieve winning the game level. 
- Winning interface: This interface appears automatically just when the player completes all the educational tasks in the game level. It also has attractive animation and music in the background that implies winning.

- Loss interface: It automatically appears just when the player fails to accomplish an educational task, or offers wrong response about the graphical objects, or else if he/she "consumes" the time allocated to the achieve all the educational tasks in the game level. This interface contains expressive animations and music in the background that signify the loss (Fig. 3).

- Designing the suitable teaching strategies for the mobile learning environment: The researcher depended on the students' use of the mobile games, In addition to a set of teaching strategies, namely collaborative learning, PowerPoint strategy, Discussion strategy.

- Defining programs of the mobile games production: The researcher determined the computer programs needed to convert all the designs of the educational electronic games into usable software. These programs are Game Marker Studio Program, Adobe Photoshop SC6 Program, Audacity Program, and Microsoft Office Word 2013 Program.

- Designing the evaluation tools: The researcher designed the evaluation instruments that fit the nature of the educational environment, which is based on teaching through using the educational electronic games in the smart mobile telephone, which were as Winner lists or lead rankings, Worksheets and mathematical achievement test that is applied directly to the students just when the experiment is over.

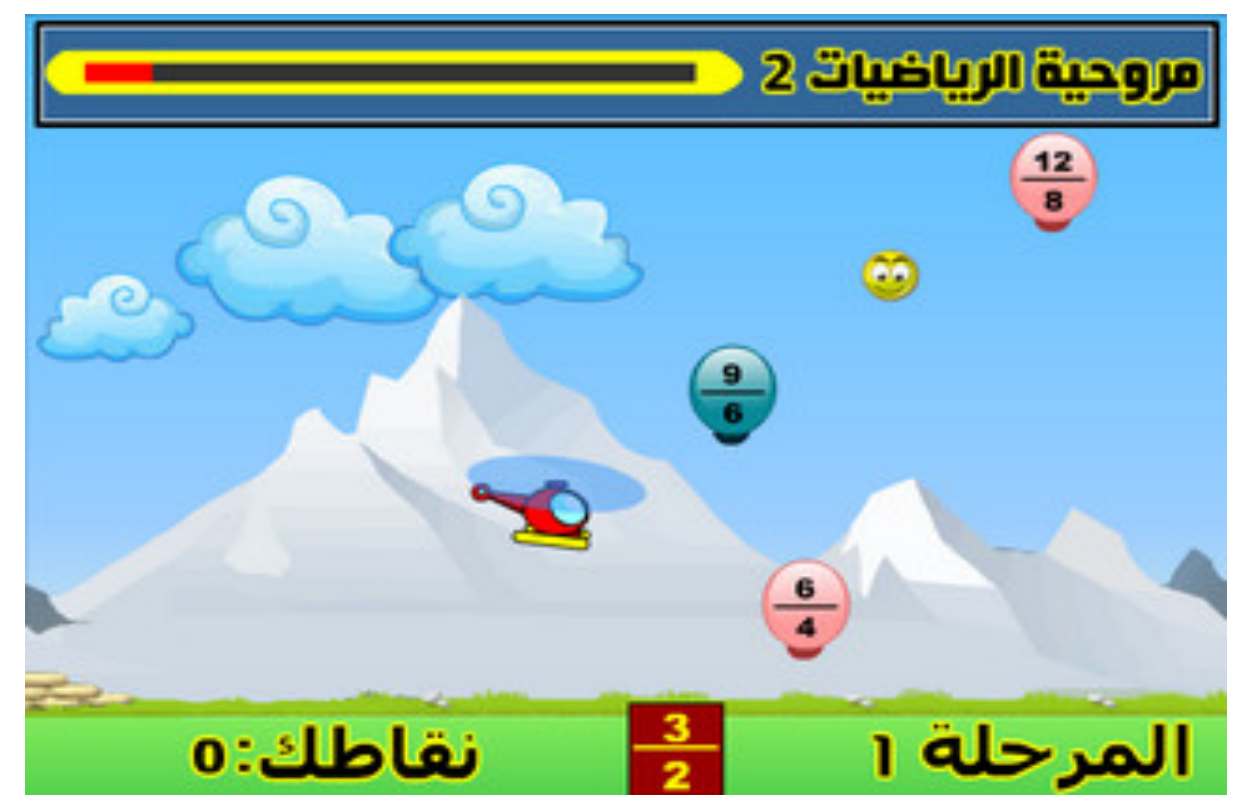

Fig. 2. 


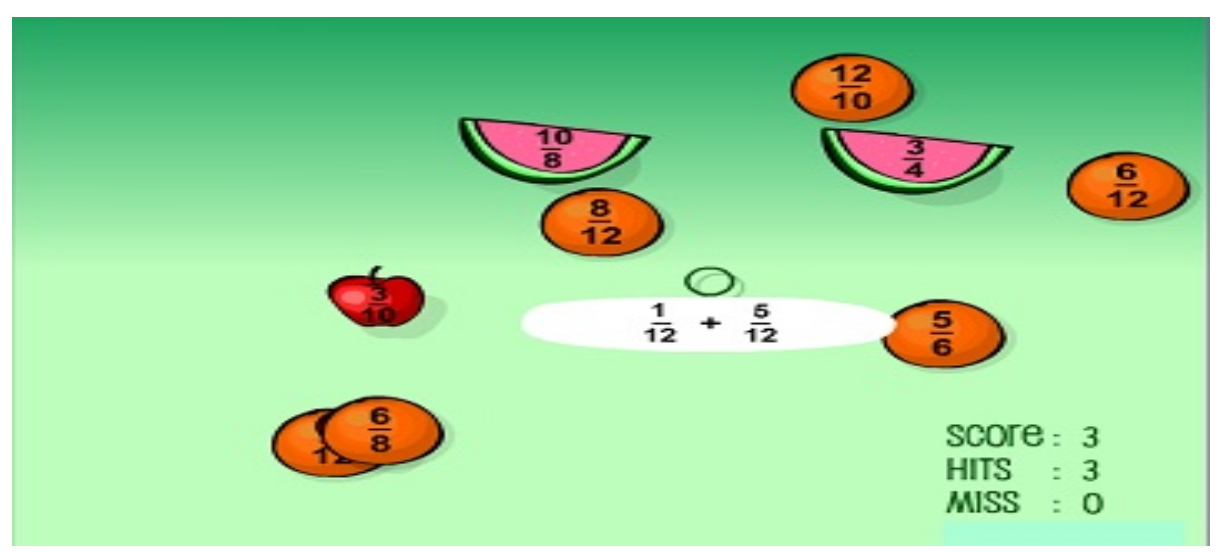

Fig. 3.

Stage three: Evaluation: This stage is connected with the mobile games following the completion of their production process, to ensure their application validity to the learners and their suitability for the use in their smart telephones. I conducted the evaluation process through presenting the mobile games for arbitration, to carry out the amendments that they may require. I further applied it to an exploratory group of twenty 5th graders to discover the difficulties and challenges that may encounter the students during the game practice using their smart mobile telephones. I discovered their need for a longer time to achieve the required tasks in the second game levels, as well as ambiguity of certain questions in the third game level, and inability of some smart mobile telephones to download the games. The researcher overcame all these problems.

After ensuring the field applicability of the games, the researcher distributed them over the experimental group students to teach them the educational material using these games in the smart mobile telephones. Following the experiment application, the post-application math achievement test was applied to both the control and experimental groups.

\subsection{Group parity}

The researcher determined the achievement by verifying that there were no statistically significant differences in the achievement among the students of the control and experimental groups by applying the achievement test to the students before the experiment was started. Therefore, the researcher conducted a (T) value for two independent samples, the value of $\mathrm{T}$ is 0.85 and the statistical significance is 0.40 , which indicates that there are no statistically significant differences due to the variable of achievement between the two study groups. 


\section{Results}

Results showed there were differences in the achievement between students in two study groups. The group taught using mobile gaming had the following results: conceptual knowledge (9.29), procedural knowledge (8.82), problem solving (8.32) and overall all test (26.44). While the group taught using, conventional method had the following results: conceptual knowledge (6.81), procedural knowledge (6.88), problem solving (6.47) and overall all test (20.16). Table (2) show these results.

Table 2. M's and SD's of the three groups

\begin{tabular}{|c|l|c|c|c|}
\hline Variable & \multicolumn{1}{|c|}{ Group } & No. & M & SD \\
\hline \multirow{2}{*}{$\begin{array}{c}\text { Conceptual Know- } \\
\text { ledge }\end{array}$} & mobile gaming & 34 & 9.29 & 0.76 \\
\cline { 2 - 5 } & Control Group & 32 & 6.81 & 0.69 \\
\hline \multirow{2}{*}{$\begin{array}{c}\text { Procedural Know- } \\
\text { ledge }\end{array}$} & mobile gaming & 34 & 8.82 & 0.97 \\
\cline { 2 - 5 } & Control Group & 32 & 6.88 & 0.91 \\
\hline \multirow{2}{*}{$\begin{array}{c}\text { Problem Solving } \\
\text { Oyyyy }\end{array}$} & mobile gaming & 34 & 8.32 & 0.81 \\
\cline { 2 - 5 } & Control Group & 32 & 6.47 & 0.88 \\
\hline \multirow{2}{*}{\begin{tabular}{c} 
Overall Test \\
\cline { 2 - 5 }
\end{tabular}} & mobile gaming & 34 & 26.44 & 1.86 \\
\cline { 2 - 5 } & Control Group & 32 & 20.16 & 1.08 \\
\hline
\end{tabular}

The (ANOVA) was employed; its results showed differences between the two study groups as follows: In the conceptual knowledge: $\mathrm{F}=191.471(\mathrm{p}<0.05)$; in the procedural knowledge: $F=70.791(\mathrm{p}<0.05)$; in problem solving: $\mathrm{F}=79.928(\mathrm{p}<0.05)$; and in the overall test: $F=276.718(p<0.05)$, as shows in Table (3).

Table 3. ANOVA to Identify the significance of the differences among the means of the two groups

\begin{tabular}{|c|l|c|c|c|c|c|c|}
\hline Source & Dependent Variable & $\begin{array}{c}\text { Sum of } \\
\text { Squares }\end{array}$ & DF & $\begin{array}{c}\text { M. } \\
\text { Square }\end{array}$ & F & Sig & $\begin{array}{c}\text { Partial Eta } \\
\text { Squared }\end{array}$ \\
\hline \multirow{3}{*}{$\begin{array}{l}\text { Teaching } \\
\text { Method }\end{array}$} & Conceptual Knowledge & 101.521 & 1 & 101.521 & 191.471 & 0.00 & 0.75 \\
\cline { 2 - 8 } & Procedural Knowledge & 62.589 & 1 & 62.589 & 70.971 & 0.00 & 0.53 \\
\cline { 2 - 9 } & Problem Solving & 56.711 & 1 & 56.711 & 79.928 & 0.00 & 0.66 \\
\cline { 2 - 9 } Error & Overall Test & 651.156 & 1 & 651.156 & 276.718 & 0.00 & 0.81 \\
\hline \multirow{3}{*}{} & Conceptual Knowledge & 33.934 & 64 & 0.53 & & & \\
\cline { 2 - 9 } & Procedural Knowledge & 56.441 & 64 & 0.88 & & & \\
\cline { 2 - 9 } & Problem Solving & 45.410 & 64 & 0.71 & & & \\
\cline { 2 - 9 } & Overall Test & 150.601 & 64 & 2.353 & & & \\
\hline
\end{tabular}

The results showed the students of the group taught using mobile gaming outperformed the control group students; this preeminence was in all the dependent variables (conceptual knowledge, procedural knowledge, problem solving and the overall test). 


\section{Discussion and Conclusion}

This study found encouraging evidence of the use of the mobile gaming to improve the students' math learning, and fill the achievement gap between the defaulter and normal students. The previous research works showed that learners will benefit the interference of technology in math teaching (Kebritchi, Hirumi \& Bai, 2010; Sedig, 2008). Nonetheless, not much is known about the effectiveness of the mobile gaming. This current study found that the use of the mobile gaming is an effective practice in providing educational support to the students inside the classrooms in the public education. In short, there is a possibility of using the well-designed mobile games to assist the students realize high achievement in mathematics.

The effect size of the mobile games use on the grand total of the test levels was high, which emphasizes the mobile games effectiveness. The researcher attributes this result to that the mobile gaming learning method, as a new learning style, raised the students' interest and increased their motivation toward learning. The games displayed the academic material in an interesting and enjoyable way, as the photos, drawings, sound effects, and motion overlap in an attractive manner, which made the student active, effective and willing to learn.

On the other hand, the mobile games allowed the student a chance of gradual and self-progress in the scientific materials, according to his/her ability in achieving the educational tasks and realizing the winning in every level of the game. The mobile games relied on stirring the spirit of the individual competition among the students, in addition to competing at the group level, which increased their interaction and willingness to achieve the educational tasks in the game level, and approach realization of winning. The mobile gaming also provided an opportunity to play without time and place constraints. Students were seen playing in the school courtyard and during the break times. They further provided instant feedback after every response, which initiated a challenge with the self and propelled him/her to continue playing to achieve winning.

The mobile games introduced the concepts to the students gradually. They handled the same concept many times in different ways, and in more than one of the game levels, which resulted in the occurrence of learning based on understanding. This assisted the student integrate the math concepts into his/her knowledge structure in an organized, retrievable manner; this explains the high effect size of conceptual knowledge among students.

The use of mobile games inside the classroom resulted in strong relation between the students and the teacher, which stimulated them to express their emotions and posit their questions free of shame or fear. This made them participate in the teachinglearning process in a positive, active and effective manner. This result is in line with many previous results, such as Rava'a and Daher (2009); Kiger, Herro and Prunty (2012).

Pursuant to the test the researcher made on the use of the mobile telephones in math learning, he strongly believes that many chances and possibilities are not yet realized. We are still at the beginning stage of the discovery of such a promising use in the educational environment. In spite of the disturbance that these systems may cause in 
the classrooms, yet the researcher believes that preventing their use in schools is not the solution. We have to continue studying pedagogy, side by side with the use of mobile telephones in the actual educational environment, and develop suitable activities that are efficiently used in these systems in the learning process.

In the light of the findings of this study, the researcher recommends employing the mobile game in teaching the math concepts, for all the educational stages, for both males and females. The Ministry of Education is required to adopt principles of gamification in education and provide relevant software's to it. It is also required to train the teachers on their use and designing and producing new mobile games that fit the objectives and content of the math curricula, which also correspond to the learners' age and psychological characteristics.

The researcher suggests conducting more studies to unfold the effect of employing the mobile gaming in developing other learning aspects, such as the different thinking styles, creative problem-solving, decision taking skills, and development of learning processes. Furthermore, the researcher suggests conducting studies to uncover the effect of the mobile games in teaching academic courses to students of different levels, such as gifted students, students with learning disabilities, and special needs students.

\section{$5 \quad$ References}

[1] Admiraal, W., Huizenga, J., Akkerman, S. \& ten Dam, G. (2011). The concept of flow in collaborative game-based learning. Computers in Human Behavior, 27(3), 1185-1194. https://doi.org/10.1016/i.chb.2010.12.013

[2] Baya'a, N. \& Daher, W. (2009). Learning Mathematics in an Authentic Mobile Environment: the Perceptions of Students. International Journal of Interactive Mobile, 3(S1), 614.https://doi.org/10.3991/ijim.v3s1.813

[3] Bicen, H. \&Kocakoyun, S. (2018). Perceptions of Students for Gamification Approach: Kahoot as a Case Study. Journal of Emerging Technologies in Learning,(13) 2, 72-93 . https://doi.org/10.3991/ijet.v13i02.7467

[4] Carpenter, T., Levi, L., Berman, P. \& Pligge, M. (2005). Developing algebraic reasoning in the elementary school. In T. A. Romberg, T. P. Carpenter \& F. Dremock (Eds.), Understanding mathematics and science matters (pp. 81-98). Mahwah, NJ: Erlbaum.

[5] Cheung, A. \& Slavin, R. (2013). The effectiveness of educational technology applications on mathematics achievement in K-12 classrooms: A meta-analysis. Educational Research Review, 9, 88-113.https://doi.org/10.1016/j.edurev.2013.01.001

[6] Christothea, H. (2018).Mobile games and science learning: A comparative study of 4 and 5 years old playing the game Angry Birds.British Journal of Educational Technology, 49 (1), 6-16. https://doi.org/10.1111/bjet.12546

[7] Chun Ou, F. (2015). Using Mobile Devices to Improve Educational Outcomes: An Analysis in Primary Education. International Journal of Learning, Teaching and Educational Research, 12(3), 28-45.

[8] Diah, N., Ehsan, K. \& Ismail, M. (2010). Discover mathematics on mobile devices using gaming approach. Procardia-Social and Behavioral Sciences, 8,670-677. https://doi.org/ 10.1016/j.sbspro.2010.12.093

[9] Fabian, K., Topping, K. \& Barron, I. (2016). Mobile technology and mathematics: effects on students' attitudes, engagement, and achievement. Journal of Computers in Education,3, 77. https://doi.org/10.1007/s40692-015-0048-8

[10] Ferri, F., D’Andrea, A., Grifoni, P. \& Guzzo, T. (2018). Distant Learning: Open Challenges and Evolution. International Journal of Learning, Teaching and Educational Research, 17(8), 78-88, https://doi.org/10.26803/ijlter.17.8.5 
[11] Franklin, T. \& Peng, L. (2008). Mobile math: Math educators and students engage in mobile learning. Journal of Computing in Higher Education, 20(2), 69-80. https://doi.org/10.1 007/s12528-008-9005-0

[12] Herodotou, C. (2017). Mobile games and science learning: A comparative study of 4 and 5 years old playing the game Angry Birds, British Journal of Educational Technology, 49 (1), 6-16. https://doi.org/10.1111/bjet.12546

[13] Huizenga, J., Admiraal, W., Akkerman, S. \& Dam, G. (2009). Mobile game-based learning in secondary education: engagement, motivation and learning in a mobile city game. Journal of Computer Assisted Learning, 25(4), 332-344. https://doi.org/10.1111/j.13652729.2009.00316.x

[14] Hursen, C. \& Bas, C (2019). Use of Gamification Applications in Science Education. InternationalJournal of Emerging Technologies in Learning, 14(1), 4-23. https://doi.org/10.3991/ijet.v14i01.8894

[15] Kebritchi, M., Hirumi, A. \& Bai, H. (2010). The effects of modern mathematics computer games on mathematics achievement and class motivation. Computers \& Education, 55(2), 427-443. https://doi/10.1016/j.compedu.2010.02.007

[16] Kiger, D., Herro, D. \& Prunty, D. (2014). Examining the Influence of a MobileLearning Intervention on Third Grade Math Achievement. Journal ofResearch on Technology in Education, 45(1), 61-82.https://doi.org/10.1080/15391523.2012.10782597

[17] Koutromanos, K. \& Lucy, A. (2014). The use of mobile games in formal and informal learning environments: a review of the literature.Educational Media International, 51 (1), 49-65. https://doi.org/10.1080/09523987.2014.889409

[18] Li, Q. \& Ma, X. (2010). A meta-analysis of the effects of computer technology on school students' mathematics learning. Educational Psychology Review, 22(3), 215-243.

[19] Miller, D. \& Robertson, D. (2010). Using a games console in the primary classroom: Effects of 'Brain Training' program on computation and self-esteem. British Journal of Educational Technology, 41(2), 242--255.https://doi.org/10.1111/j.1467-8535.2008.00918.x

[20] Miller, D. \& Robertson, D. (2011). Educational benefits of using game consoles in a primary classroom: A randomised controlled trial. British Journal of Educational Technology, 42(5), 850--864.https://doi.org/10.1111/j.1467-8535.2010.01114.x

[21] Nicol, A. (2017). Using Gaming to Make Statistics fun. College Teaching, 65(1), 39-39. https://doi: 10.1080/87567555.2016.1222576

[22] Roberts, N. \& Vänskä, R. (2011). Challenging assumptions: mobile learning for mathematics project in South Africa. Distance Education, 32(2), 243-259.https://doi.org/10.1080/ 01587919.2011 .584850

[23] Sedig, K. (2008). From play to thoughtful learning: A design strategy to engage children with mathematical representations. Journal of Computers in Mathematics and Science Teaching, 27 (1), 65-101.

[24] Segal, A. (2011). Do gestural interfaces promote thinking? Embodied interaction: Congruent gestures and direct touch promote performance in math. Unpublished dissertation, Columbia University, New York.

[25] Seow, p. \& Wong, S. (2016). Using a mobile gaming app to enhance accounting education. Journal of Education for Business, 91 (8), 434-439. https://doi.org/10.1080/08832323.2016. 1256264

[26] Sirkemaa, S. \& Varpelaide, H. (2018). The Need for Digital Learning Environments. International Journal of Learning, Teaching and Educational Research, 17(6) 167-181. https://doi.org/10.26803/ijlter.17.6.11

[27] Slavin, R. \& Lake, C. (2008). Effective programs in elementary mathematics: A best evidence synthesis. Review of Educational Research, 78(3), 427-515.https://doi.org/10. $3102 \% 2 \mathrm{~F} 0034654308317473$

[28] Wang, C., Huang, Y. \& Hsu, K. (2017). Developing a mobile game to support students in learning color mixing in design education.Advances in Mechanical Engineering, 9 (2)16.https://doi.org/10.1177\%2F1687814016685226

[29] Wijers, M., Jonker, V. \& Drijvers, P. (2010). Mobile Math: exploring mathematics outside the classroom. ZDM, 42(7), 789- 799.https://doi.org/10.1007/s11858-010-0276-3

[30] Zanchi, C., Presser, A. \& Vahey, P. (2013). Next generation preschool math demo: tablet games for preschool classrooms. In Proceedings of the 12th International Conference on In- 
teraction Design and Children, pp. 527-530. ACM. https://doi.org/10.1145/2485760. 2485857

[31] Zaranis, N., Kalogiannakis, M. \& Papadakis, S. (2013). Using Mobile Devices for Teaching Realistic Mathematics in Kindergarten Education. Creative Education, 4(07), 1.1-10. https://doi.org/10.4236/ce.2013.47A1001

[32] Zhao, X. \& Okamoto, T. (2009). A Personalized Mobile Mathematics Tutoring System for Primary Education. Journal of the Research Center for Educational Technology, 4(1), 6167.

\section{Author}

Mohammad Al-Khateeb Associate Professor in Curriculum and Method of Teaching Mathematics, He works at the Hashemite University in Jordan and previously worked at Taibah University in the K.S.A. He is interested in integrating technology into mathematics education.

Article submitted 2019-01-13. Resubmitted 019-02-28. Final acceptance 2019-03-03. Final version published as submitted by the authors. 